\title{
Model Pemberdayaan Masyarakat Bidang Kesehatan, Studi Program Desa Siaga
}

\author{
Community Empowerment Model in Health Sector, Study on Village \\ Preparadness Program
}

\author{
Endang Sutisna Sulaeman* Ravik Karsidi** Bhisma Murti** Drajat Tri Kartono** Waryana*** Rifai Hartanto*
}

*Bagian Ilmu Kesmas FK Universitas Sebelas Maret Surakarta, **Prodi Penyuluhan Pembangunan/Pemberdayaan Masyarakat Pascasarjana Universitas Sebelas Maret Surakarta, ***Bagian Gizi Poltekkes Kemenkes Yogyakarta

\begin{abstract}
Abstrak
Sejak tahun 2006, Departemen Kesehatan meluncurkan kebijakan program Desa Siaga. Tampaknya, kebijakan tersebut tidak mampu memberdayakan masyarakat dalam mengidentifikasi dan memecahkan masalah kesehatan pada level komunitas (desa). Penelitian ini bertujuan merumuskan model pemberdayaan masyarakat bidang kesehatan pada program Desa Siaga. Sasaran penelitian adalah Forum Kesehatan Desa dan Pos Kesehatan Desa Siaga di 30 desa di Kabupaten Karanganyar, Jawa Tengah. Metode yang digunakan dalam penelitian ini adalah survei dan studi kasus. Hasil penelitian menunjukkan faktor-faktor yang berhubungan dengan kemampuan masyarakat dalam mengidentifikasi masalah kesehatan dan kemampuan masyarakat dalam memecahkan masalah kesehatan. Model pemberdayaan masyarakat bidang kesehatan meliputi kemampuan mengidentifikasi dan memecahkan masalah kesehatan. Faktor-faktor internal dan eksternal komunitas pada level anggota masyarakat, institusi masyarakat, kepemimpinan masyarakat, dan akses informasi kesehatan memiliki peran penting dalam pemberdayaan masyarakat bidang kesehatan.
\end{abstract}

Kata kunci: Desa siaga, kebijakan, pemberdayaan masyarakat

\footnotetext{
Abstract

Since 2006, the Health Department had launched the Village Preparedness program policy. But, this policy apparently not capable of empowering the community in identifying and solving the health problem at community (village) level. The objective of research is to formulate the community empowerment model in health in the Village Preparedness program. The targets of research were the Village Health Forum and Village Health Post in 30 Village Preparedness in Karanganyar Regency, Central Java. The method involving survey and case study. The case study showed factors related to community capability of identifying health problem and community capability of solving the health problems. The community empowerment model in health including the capabilities of identifying and of solving the health problems. The community internal and external factors at members of commu-
}

nity level, community institution, community leadership, and information access played important role in community empowerment in health.

Keywords: Village preparedness, policy, community empowerment

\section{Pendahuluan}

Kesejahteraan masyarakat menurut United Nations Development Program (UNDP) diukur dengan Indeks Pembangunan Manusia (IPM). IPM merupakan indikator komposit dari tiga indikator sektor pembangunan: pendidikan, kesehatan, dan ekonomi. IPM Indonesia tahun 2010 berada pada peringkat 108, sementara tahun 2011 turun ke peringkat $124 .{ }^{1}$ Fakta ini menunjukkan makin merosotnya kualitas hidup manusia Indonesia. Konferensi Tingkat Tinggi (KTT) Millenium Perserikatan Bangsa-Bangsa (PBB) sepakat untuk mengadopsi Deklarasi Milenium. Tujuan Deklarasi disebut Tujuan Pembangunan Milenium (Millennium Development Goals-MDGs), menempatkan manusia sebagai fokus utama pembangunan. ${ }^{2,3}$

Menurut Susilo, ${ }^{4}$ Indonesia berkali-kali masuk kategori negara yang lamban dalam mencapai MDGs. Sumber kelambanan ditunjukkan dari masih tingginya angka kematian ibu dan angka kematian balita, belum teratasinya laju penularan HIV/AIDS, rendahnya pemenuhan air bersih dan sanitasi yang buruk, belum adanya pengakuan inisiatif masyarakat, pemerintah RI belum pernah mendorong rasa kepemilikan bersama MDGs kepada rakyatnya, sangat kuat kesan bahwa pen-

Alamat Korespondensi: Bagian Ilmu Kesehatan Masyarakat Fakultas Kedokteran Universitas Sebelas Maret, Jl. Ir. Sutami No. 36 A Kentingan, Surakarta 57126, Hp.081320545707,e-mail: sutisnaend_dr@yahoo.com 
capaian MDGs identik dengan pelaksanaan program pemerintah. Menyimak kenyataan tersebut, sejak tahun 2006, Departemen Kesehatan RI melakukan upaya terobosan yang memiliki daya ungkit bagi peningkatan derajat kesehatan penduduk Indonesia dan untuk akselerasi pencapaian MDGs yaitu melalui kebijakan program Desa Siaga. Desa Siaga adalah suatu kondisi masyarakat desa yang memiliki kesiapan sumber daya dan kemampuan serta kemauan untuk mencegah dan mengatasi masalah kesehatan, bencana dan kegawatdaruratan kesehatan secara mandiri. ${ }^{5}$

Masalah pemberdayaan masyarakat bidang kesehatan pada program Desa Siaga adalah sebagai berikut: Pertama, paradigma sehat sebagai paradigma pembangunan kesehatan telah dirumuskan, namun belum dipahami dan diaplikasi semua pihak. Kedua, undang-undang RI Nomor 32 Tahun 2004 tentang Pemerintahan Daerah menetapkan daerah (kabupaten/kota) memegang kewenangan penuh dalam bidang kesehatan, namun kewenangan tersebut belum berjalan optimal. Ketiga, revitalisasi puskesmas dan posyandu hanya diartikan dengan pemenuhan fasilitas sarana. Keempat, dinas kesehatan kabupaten/kota lebih banyak melakukan tugastugas administratif. Kelima, keterlibatan masyarakat bersifat semu yang lebih berkonotasi kepatuhan daripada partisipasi dan bukan pemberdayaan masyarakat.

Pemberdayaan masyarakat bidang kesehatan mengemuka sejak dideklarasikannya Piagam Ottawa. Piagam Ottawa menegaskan bahwa partisipasi masyarakat merupakan elemen utama dalam pemberdayaan masyarakat bidang kesehatan. Selanjutnya, Konferensi Internasional Promosi Kesehatan ke-7 di Nairobi, Kenya, menegaskan kembali pentingnya pemberdayaan masyarakat bidang kesehatan dengan menyepakati perlunya: membangun kapasitas promosi kesehatan, penguatan sistem kesehatan, kemitraan dan kerjasama lintas sektor, pemberdayaan masyarakat, serta sadar sehat dan perilaku sehat. ${ }^{6}$

Pemberdayaan didefinisikan sebagai suatu proses membuat orang mampu meningkatkan kontrol atas keputusan dan tindakan yang memengaruhi kesehatan masyarakat, bertujuan untuk memobilisasi individu dan kelompok rentan dengan memperkuat keterampilan dasar hidup dan meningkatkan pengaruh pada hal-hal yang mendasari kondisi sosial dan ekonomi. Sementara itu, menurut pemerintah RI dan United Nations International Children's Emergency Funds, pemberdayaan masyarakat adalah segala upaya fasilitas yang bersifat noninstruktif untuk meningkatkan pengetahuan dan kemampuan masyarakat agar mampu mengidentifikasi masalah, merencanakan, dan melakukan pemecahannya dengan memanfaatkan potensi setempat dan fasilitas yang ada, baik dari instansi lintas sektor maupun LSM dan tokoh masyarakat. ${ }^{7}$
Sepuluh model pemberdayaan masyarakat bidang kesehatan diformulasikan sebagai berikut. Pertama, model pengembangan lokal yaitu pemberdayaan masyarakat sejalan dengan model pengembangan lokal sebagai upaya pemecahan masalah masyarakat melalui partisipasi masyarakat dengan pengembangan potensi dan sumber daya lokal. ${ }^{8}$ Kedua, model promosi kesehatan dilakukan melalui empat pendekatan, yaitu persuasi (bujukan/ kepercayaan) kesehatan, konseling personal dalam kesehatan, aksi legislatif, dan pemberdayaan masyarakat. Ketiga, model promosi kesehatan perspektif multidisiplin mempertimbangkan lima pendekatan meliputi medis, perilaku, pendidikan, pemberdayaan, dan perubahan sosial. ${ }^{9}$ Keempat, model pelayanan kesehatan primer berbasis layanan masyarakat menurut Ife, masyarakat harus bertanggung jawab dalam mengidentifikasi kebutuhan dan menetapkan prioritas, merencanakan dan memberikan layanan kesehatan, serta memantau dan mengevaluasi layanan kesehatan. ${ }^{10}$ Kelima, model pemberdayaan masyarakat meliputi partisipasi, kepemimpinan, keterampilan, sumber daya, nilai-nilai, sejarah, jaringan, dan pengetahuan masyarakat. ${ }^{11}$

Keenam, model pengorganisasian masyarakat yaitu hubungan antara pemberdayaan, kemitraan, partisipasi, responsitas budaya, dan kompetensi komunitas. Ketujuh, model determinan sosial ekonomi terhadap kesehatan meliputi pendidikan, pekerjaan, pendapatan, dan modal atau kekayaan yang berhubungan satu sama lain dengan kesehatan. ${ }^{12}$ Kedelapan, model kesehatan dan ekosistem masyarakat interaksi antara masyarakat, lingkungan, dan ekonomi dengan kesehatan. ${ }^{13}$ Kesembilan, model determinan lingkungan kesehatan individual dan masyarakat determinan lingkungan kesehatan individual meliputi lingkungan psikososial, lingkungan mikrofisik, lingkungan ras/kelas/gender, lingkungan perilaku, dan lingkungan kerja. ${ }^{13}$ Sementara itu, determinan lingkungan kesehatan masyarakat meliputi lingkungan politik/ekonomi, lingkungan makrofisik, tingkat keadilan sosial dan keadilan dalam masyarakat, serta perluasan kontrol dan keeratan masyarakat. Kesembilan, model penanggulangan penyakit berbasis keluarga yaitu pemeliharaan kesehatan dilakukan secara swadaya dan mandiri oleh keluarga melalui penumbuhan kesadaran, peningkatan pengetahuan, dan keterampilan memelihara kesehatan. ${ }^{14}$ Kesepuluh, model pembangunan kesehatan masyarakat desa (PKMD).

\section{Metode}

Penelitian ini bersifat explanatory study yaitu berusaha menjelaskan pengaruh dan hubungan antarvariabel berdasarkan kenyataan empiris dan diberikan penjelasan analisis kualitatif. Dengan demikian, metode penelitian ini menggunakan pendekatan metode gabungan (mixed methods), yaitu memadukan pendekatan kuantitatif dan 
kualitatif. Pendekatan kuantitatif lebih dominan, sementara pendekatan kualitatif dijadikan sebagai penunjang (dominant quantitative less qualitative). ${ }^{15}$ Penelitian kuantitatif dilakukan melalui penelitian survei, sedangkan penelitian kualititatif dilakukan dengan studi kasus.

Unit analisis adalah Desa Siaga, sedangkan unit pengamatan adalah bidan pos kesehatan desa (Poskesdes) dan forum kesehatan desa/kelurahan (FKD/FKK). Pengujian hipotesis dilakukan dengan analisis jalur yang terlebih dahulu membakukan penduga koefisiensi regresi yang distandardisasikan (standardized path coefficient) sebagai koefisien jalur (path regression coefficient) yang dinotasikan dengan nilai $B$, yang menunjukkan sumbangan pengaruh langsung dari suatu variabel eksogen terhadap variabel endogen.

Data penelitian kuantitatif diperoleh melalui kuesioner tertutup dengan responden bidan poskesdes dan FKD/FKK di 30 Desa Siaga. Studi kasus dilakukan di dua Desa Siaga, yaitu Desa Siaga Mandiri dan Desa Siaga Pratama. Pengumpulan data studi kasus dilakukan melalui wawancara mendalam, observasi partisipasi, dan kajian dokumen. Wawancara mendalam dilakukan terhadap 107 informan $(n=107)$ terdiri dari 78 orang informan masyarakat $(\mathrm{n}=78)$ dan 29 orang informan petugas kesehatan $(\mathrm{n}=29)$. Observasi partisipasi dilakukan di dua Poskesdes. Kajian dokumen dilakukan terhadap pedoman, kebijakan, perencanaan, dan hasil kegiatan program Desa Siaga.

\section{Hasil}

\section{Kemampuan Mengidentifikasi Masalah Kesehatan Lokal}

Persepsi responden menunjukkan bahwa kemampuan mengidentifikasi masalah kesehatan sekitar $72,67 \%$ tergolong cukup, akses informasi kesehatan sekitar 82,92\% tergolong baik, kepemimpinan sekitar $67,5 \%$ tergolong cukup), dan SMD sekitar 67,22\% tergolong cukup dengan pengelompokan lebih dari $80 \%$ dikategorikan baik, antara $64 \%-80 \%$ dikategorikan cukup. Pengaruh keempat variabel eksogen menunjukkan satu variabel yang tidak signifikan, yaitu tingkat pendidikan. Selanjutnya, dilakukan pengujian hipotesis dengan analisis jalur. Berdasarkan hasil uji hipotesis, berbagai faktor yang berhubungan secara signifikan dengan kemampuan mengidentifikasi masalah kesehatan lokal pada program Desa Siaga meliputi akses informasi kesehatan, kepemimpinan, dan Survei Mawas Diri (SMD). Besar kontribusi akses informasi pada kemampuan mengidentifikasi masalah kesehatan $29,48 \%$, kepemimpinan $41,86 \%$, SMD 40,07\%, secara simultan 53,2\% (Tabel 1).

\section{Studi Kasus}

Faktor-faktor yang berhubungan dengan kemampuan mengidentifikasi masalah kesehatan berdasarkan studi kasus meliputi tingkat pendidikan, pengetahuan, ke-
Tabel 1. Analisis Jalur Kemampuan Mengidentifikasi Masalah Kesehatan pada Program Desa Siaga

\begin{tabular}{lcc}
\hline \multirow{2}{*}{ Varibel Bebas } & \multicolumn{2}{c}{ Varibel Terikat } \\
\cline { 2 - 3 } & $\mathbf{B}$ & Nilai p \\
\hline Tingkat pendidikan & 0,02 & 0,838 \\
Akses informasi kesehatan & 0,23 & $\left.0,049^{*}\right)$ \\
Kepemimpinan & 0,33 & $\left.0,013^{*}\right)$ \\
Survei mawas diri & 0,31 & $\left.0,017^{*}\right)$ \\
\hline
\end{tabular}

Keterangan:

$B($ nilai koefisien jalur $)=$ Standardized path coefficient (koefisiensi regresi yang distandarisasikan)

nilai $\mathrm{p} \quad=$ signifikansi

*) $\quad=$ berhubungan secara signifikan

sadaran, kepedulian, kebiasaan, akses informasi kesehatan, peran petugas kesehatan, peran fasilitator, kepemimpinan, modal sosial, dan SMD.

“...Tingkat pendidikan berhubungan dengan kemampuan mengidentifikasi masalah kesehatan. Warga masyarakat yang berpendidikan tinggi akan mengenal masalah kesehatan..." (Informan 3 Puskesmas Karanganyar)

“...Pengetahuan dukun bayi dalam menolong persalinan, menjadikan dia dapat membantu menolong persalinan..."(Informan 4 Desa Jatiroyo)

"...Ada kesadaran masyarakat yang dipicu oleh penyuluhan petugas kesehatan, berhubungan dengan kemampuan mengidentifikasi masalah kesehatan..." (Informan 1 Puskesmas Jatipuro)

"...Masyarakat yang peduli terhadap kesehatan, akan mampu mengidentifikasi masalah kesehatan..." (Informan 5 Puskesmas Karangnyar)

"...Terdapat kebiasaan warga masyarakat desa menjenguk orang sakit. Dengan tradisi menengok orang sakit ini, warga masyarakat mengenal penyakit dan masalah kesehatan yang diderita oleh orang sakit tersebut...” (Informan 6 Desa Jatiroyo)

"...Akses informasi kesehatan berhubungan dengan kemampuan mengidentifikasi masalah kesehatan. Kalau ada warga masyarakat mengalami kejadian seperti di TV, ada unggas mati, masyarakat mampu mengidentifikasi masalah kesehatan, langsung melaporkan ke Bidan Poskesdes... "(Informan 5 Puskesmas Jatipuro)

“...Kemampuan mengidentifikasi masalah kesehatan lokal pada program Desa Siaga diperoleh dari pendampingan oleh petugas kesehatan pada saat kunjungan ke desa..." (Informan 3 Puskesmas Jatipuro)

“...Fasilitator program Desa Siaga berperan sebagai pendamping yaitu mendampingi proses mengidentifikasi masalah kesehatan ..."(Informan 9 Desa Siaga/DS3 desa Jatipuro)

“...Pemimpin harus bermasyarakat, memberikan contoh keteladanan dan turut serta dalam mengidentifikasi 
masalah kesehatan. Kepemimpinan Pak Lurah dan aparatur desa sangat berpengaruh terhadap kemampuan mengidentifikasi masalah kesehatan..." (Informan 7 kelurahan Gayamdompo)

“...Ada kekerabatan, kedekatan, dan saling mengenal antarwarga masyarakat berhubungan dengan kemampuan mengidentifikasi masalah kesehatan. Tetangga memberikan saran, nasihat, atau informasi masalah kesehatan atau penyakit yang diderita oleh tetangganya...”(Informan 6 Puskesmas Jatipuro)

“...Manfaat melakukan survei mawas diri adalah meningkatkan kemampuan masyarakat dalam mengidentifikasi masalah. Dengan survei mawas diri masyarakat dapat menyampaikan masalah kesehatan dan mengenal masalah kesehatan..."(Informan 1 Desa Jatipuro)

\section{Kemampuan Pemecahan Masalah Kesehatan Lokal Penelitian Kuantitatif}

Persepsi responden menunjukkan bahwa kemampuan pemecahan masalah kesehatan lokal sekitar 73,38\%, modal sosial sekitar 75,7\% , musyawarah masyarakat desa sekitar 66,92\%, dan partisipasi masyarakat 64,08\%, semuanya tergolong cukup, tetapi sumber daya lokal $61,94 \%$ tergolong kurang.

\section{Analisis Jalur}

Analisis pengaruh antara keenam variabel eksogen menemukan satu variabel yang tidak signifikan adalah tingkat pendidikan. Selanjutnya, hasil uji hipotesis dengan analisis jalur berdasarkan hasil uji hipotesis 2 disimpulkan bahwa faktor-faktor yang berhubungan secara signifikan dengan kemampuan pemecahan masalah kesehatan lokal pada program Desa Siaga meliputi modal sosial dan partisipasi masyarakat. Besar kontribusi modal sosial pada kemampuan pemecahan masalah kesehatan $58,98 \%$, partisipasi masyarakat $51,69 \%$, secara simultan $64,2 \%$ (Tabel 2).

\section{Studi Kasus}

Faktor-Faktor yang berhubungan dengan pemecahan masalah kesehatan pada program Desa Siaga berdasarkan studi kasus meliputi tingkat pendidikan, pengetahuan, kesadaran, kepemimpinan, status ekonomi, modal sosial, partisipasi masyarakat, sumber daya lokal, musyawarah masyarakat desa, peran petugas kesehatan, peran fasilitator, peran pemerintahan desa, peran instansi pemerintah di tingkat kecamatan dan kabupaten, dan dukungan dana pemerintah.

“...Tingkat pendidikan sangat berpengaruh terhadap pemecahan masalah kesehatan. Semakin tinggi tingkat pendidikan, semakin mampu melakukan pemecahan masalah kesehatan...”(Informan 1 Puskesmas Jatipuro)

“...Adanya pengetahuan tentang kesehatan yang
Tabel 2. Hasil Analisis Jalur Variabel Bebas terhadap Kemampuan Pemecahan Masalah Kesehatan pada Program Desa Siaga

\begin{tabular}{lll}
\hline \multirow{2}{*}{ Varibel Bebas } & \multicolumn{2}{c}{ Varibel Terikat } \\
\cline { 2 - 3 } & $\mathbf{B}$ & nilai p \\
\hline Tingkat pendidikan & $-0,14$ & 0,288 \\
Kepemimpinan & 0,04 & 0,704 \\
Tingkat pendapatan & 0,03 & 0,743 \\
Modal sosial & 0,41 & $\left.0,014^{*}\right)$ \\
Partisipasi masyarakat & 0,72 & $\left.0,1^{*}\right)$ \\
Sumber daya lokal & $-0,02$ & 0,891 \\
Musyawarah masyarakat desa & 0,19 & 0,296 \\
\hline
\end{tabular}

dimiliki warga masyarakat menjadikan mereka tergerak untuk melakukan pemecahan masalah-masalah kesehatan..." (Informan 2 Kelurahan Gayamdompo)

"...Kesadaran terhadap kesehatan, menjadi pendorong untuk melakukan pemecahan masalah kesehatan..." (Informan 2 Kelurahan Gayamdompo)

"...Seorang pemimpin yang baik adalah pemimpin yang melekat dan selalu membimbing warganya dalam pemecahan masalah kesehatan...” (Informan 3 Desa Jatipuro)

"...Kalau warga masyarakat sudah tercukupi kebutuhan primernya, mereka bisa diajak melakukan pemecahan masalah kesehatan. Pemecahan masalah kesehatan tidak hanya dipengaruhi kesadaran atau pengetahuan semata, namun juga harus ada dukungan logistik...”(Informan 1 Puskesmas Karanganyar)

“...Terdapat hubungan kekerabatan yang dijalin melalui silaturahmi, misalnya bila ada warga yang sakit, maka kita akan besuk, dan sebaliknya, sehingga terjadi timbal balik. Setiap masalah diselesaikan di forum rapat. Setelah pertemuan ada kegiatan, setiap kegiatan ada yang menanganinya..."(Informan 2 Desa Jatiroyo)

“...Masalah kesehatan sangat kompleks, diperlukan partisipasi masyarakat dalam pemecahan masalah kesehatan. Partisipasi warga desa sangat bagus, hal ini ditunjukkan dalam kehadiran pada penyuluhan kesehatan. Dengan kehadiran tersebut masyarakat dapat meningkatkan pengetahuan tentang masalah kesehatan..."(Informan 1 Puskesmas Jatipuro)

"...Dana juga dibutuhkan, kita mengimbau agar pendanaan untuk program Desa Siaga dimasukkan dalam RAPB Desa. Kemampuan pemecahan masalah kesehatan lokal dipengaruhi oleh adanya kejelian menggali potensi masyarakat..."(Informan 1 Puskesmas Jatipuro)

"...Setelah melaksanakan SMD kemudian dilakukan MMD untuk menentukan prioritas dari masalah kesehatan yang ditemukan..." (Informan 1 Puskesmas Jatipuro)

“...Peran petugas kesehatan, mulai dari kepala Dinas Kesehatan Kabupaten, Kepala Puskesmas, dan 
staf Puskesmas serta Bidan Poskesdes berhubungan dengan kemampuan pemecahan masalah kesehatan..." (Informan 1 Puskesmas Jatipuro)

“...Fasilitator berperan sebagai pendamping yaitu mendampingi proses pemecahan masalahan kesehatan, membantu memperoleh sumber daya yang diperlukan, membantu memilih pemecahan masalah kesehatan yang sesuai dengan kondisi masyarakat..." (Informan 1 Puskesmas Jatipuro)

“...Peranan aparatur pemerintahan desa antara lain membuat kebijakan desa yang mendukung program Desa Siaga termasuk dukungan dana, ikut terlibat aktif dalam sosialisasi program Desa Siaga dan pemanfaatan Poskesdes oleh masyarakat, mendorong munculnya partisipasi masyarakat dalam program Desa Siaga, memimpin pelaksanaan kegiatan program Desa Siaga di tingkat desa..." (Informan 3 desa Jatipuro)

“...Tim Pembina program Desa Siaga tingkat kecamatan berperan melakukan sosialisasi program Desa Siaga dan menyampaikan masalah-masalah kesehatan yang ada di wilayah kecamatan, melakukan pemantauan dan pembinaan dengan koordinasi dan petunjuk Camat...” (Informan 1 Puskesmas Jatipuro)

"...Peran pemerintah daerah kabupaten berhubungan dengan kemampuan pemecahan masalah kesehatan lokal pada program Desa Siaga, yaitu memberikan dukungan kebijakan, sarana, dan dana, mendorong masyarakat untuk memanfaatkan Poskesdes, melakukan pembinaan kegiatan Desa Siaga..." (Informan 1 Puskesmas Karanganyar)

“...Pemecahan masalah kesehatan lokal pada program Desa Siaga didukung oleh adanya stimulan dana dari APBD Kabupaten dan bantuan dari Depkes Pusat melalui Bantuan Operasional Puskesmas..." (Informan 1 Puskesmas Jatipuro)

\section{Pembahasan}

Pendidikan dan melek huruf memengaruhi kesehatan. ${ }^{2}$ Pendidikan berpengaruh langsung terhadap kesehatan. ${ }^{12}$ Tingkat pendidikan ditetapkan sebagai determinan lingkungan kesehatan. ${ }^{13}$ Faktor pengetahuan dalam pemberdayaan masyarakat dimasukkan pula sebagai determinan lingkungan kesehatan. ${ }^{11}$ Model penanggulangan penyakit berbasis keluarga dirumuskan melalui peningkatan pengetahuan dan keterampilan, di samping penumbuhan kesadaran. ${ }^{14}$ Akses informasi kesehatan meliputi pengetahuan tentang kesehatan. ${ }^{2}$

Proses pemberdayaan masyarakat perlu didampingi oleh fasilitator yang berperan untuk memengaruhi proses pengambilan keputusan yang dilakukan oleh masyarakat dalam mengadopsi inovasi. ${ }^{14}$ Modal sosial berhubungan dengan kemampuan mengidentifikasi masalah kesehatan melalui pertukaran informasi seperti tetangga memberikan saran satu sama lain, memberikan nasihat atau informasi untuk mendapatkan pelayanan kesehatan. ${ }^{16}$ Menurut metode, membangun konsensus seperti SMD meningkatkan kepedulian dan tekad warga masyarakat untuk melakukan transformasi, memungkinkan warga untuk menghormati dan memahami sudut pandang dan pengalaman setiap warga masyarakat. ${ }^{17}$

Pendidikan memberikan keterampilan hidup dan membuka peluang untuk pemecahan masalah kesehatan. ${ }^{18}$ Perempuan yang menyelesaikan pendidikan dasar hampir lima kali lebih mungkin untuk memilih bidan terampil pada saat persalinannya dibandingkan perempuan kurang berpendidikan. ${ }^{19}$ Selanjutnya, wanita dengan pendidikan dasar lengkap hampir tiga kali lebih mungkin untuk melakukan empat kali kunjungan perawatan antenatal (K4) dan dua kali lebih mungkin untuk menggunakan kontrasepsi modern dibandingkan wanita yang tidak atau kurang tingkat pendidikannya.

Masyarakat lokal memiliki pengetahuan, kearifan, dan keahlian. ${ }^{9}$ Peningkatan kesadaran merupakan salah satu prinsip dalam pemberdayaan masyarakat. ${ }^{10}$ Kepemimpinan lokal efektif mengembangkan kelompok masyarakat setidaknya apabila memiliki empat prasyarat yaitu terpercaya, kompeten, komunikatif, dan memiliki komitmen kerjasama yang tinggi. ${ }^{20}$ Peningkatkan kompetensi kepemimpinan komunitas harus difokuskan pada pengambilan keputusan secara partisipatif, melakukan perencanaan perubahan sosial, proses perubahan yang direncanakan harus dimengerti dan bisa dilaksanakan secara luas oleh masyarakat, serta potensi kemampuan kepemimpinan diperluas pada populasi. Kepemimpinan merupakan salah satu kunci keberhasilan pemberdayaan masyarakat. Bila kepemimpinan desa itu peduli, jujur dan tulus hati, bertanggung jawab, amanah, dan tanggap, maka program pemberdayaan masyarakat bidang kesehatan berhasil.

Penelitian menunjukkan hubungan yang signifikan antara kelas sosial dengan kesehatan. ${ }^{21}$ Hubungan antara pendapatan dengan kesehatan berbentuk kurva linier, yang menggambarkan diminishing return. ${ }^{12}$ Penelitian lintas negara menemukan hubungan yang kuat antara pendapatan yang tidak memadai dengan kesehatan. ${ }^{12}$ Selanjutnya menurut Kawachi et al.,22 modal sosial dapat memengaruhi kesehatan seperti halnya determinan sosial dan lingkungan. Penelitian Hawe et al., ${ }^{16}$ dan Yuasa et al., 23 membuktikan bahwa modal sosial melalui jaringan sosial dan komunitas berdampak pada kualitas perlindungan kesehatan. Penelitian lain melaporkan bahwa tingkat ketidakpercayaan menunjukkan hubungan yang kuat dengan angka kematian sesuai umur $(r=0,79$, $p<0,001) .{ }^{24}$ Tingkat kepercayaan yang rendah berhubungan dengan angka tertinggi dari bagian terbesar penyebab kematian utama, termasuk penyakit jantung koroner dan stroke.

Penelitian menemukan bahwa dalam pemberdayaan 
masyarakat bidang kesehatan yang paling utama adalah partisipasi, selain pengetahuan, keterampilan, sumber daya, visi bersama, sensitivitas komunitas, dan komunikasi. ${ }^{17}$ Menurut Talbot et al., ${ }^{25}$ keuntungan partisipasi masyarakat bagi perorangan adalah menumbuhkan percaya diri, memperoleh keterampilan baru, dan memberdayakan, serta berhubungan secara positif dengan data morbiditas dan mortalitas. Sementara, keuntungan bagi masyarakat adalah warga lebih terdidik dan masyarakat lebih bersatu padu, serta mengidentifikasi dan memobilisasi sumber daya. Sementara itu, sulit bagi pengembangan pemberdayaan masyarakat bidang kesehatan tanpa bantuan eksternal dan dukungan politik. ${ }^{17}$

\section{Rumusan Model Pemberdayaan Masyarakat Bidang Keseha- tan pada Program Desa Siaga/DS3 yang Direkomendasikan}

Pemodelan merupakan salah satu alat untuk memudahkan pemahaman kompleksitas dan kerumitan teori. Pemodelan bertujuan memberikan gambaran yang sederhana untuk menjelaskan teori. Pemodelan sebagai cara untuk membantu merumuskan suatu teori dan menjelaskan hubungan unsur-unsurnya. Setelah hasil penelitian dianalisis secara deduktif, selanjutnya disimpulkan melalui analisis induktif, sehingga menghasilkan model yang bersifat umum. Model yang aplikatif adalah model yang berguna. Agar model yang dihasilkan dapat berguna, model yang dirumuskan harus bersifat umum, sehingga model dapat digeneralisasi dan dapat digunakan di tempat lain (transferability - validitas eksternal).

Dalam rangka penyederhanaan konseptualisasi model pemberdayaan masyarakat bidang kesehatan yang direkomendasikan, dilakukan kategorisasi variabel yang dikelompokkan ke dalam variabel masukan, proses, dan keluaran. ${ }^{4}$ Masukan pemberdayaan terdiri dari faktor internal dan faktor eksternal komunitas. Faktor internal komunitas meliputi tingkat pendidikan, pengetahuan, kesadaran, kepedulian, kebiasaan, dan status ekonomi, kepemimpinan, modal sosial, partisipasi masyarakat, sumber daya lokal, survei mawas diri, dan musyawarah masyarakat desa. Faktor eksternal komunitas meliputi akses informasi kesehatan, peran petugas kesehatan, peran fasilitator program kesehatan, peran pemerintahan desa, peran instansi pemerintah di tingkat kecamatan dan kabupaten, dan dukungan dana pemerintah.

Adapun proses pemberdayaan meliputi proses pemberdayaan dan pemanfaatan sumber daya di dalam masyarakat yang dilakukan terhadap faktor internal komunitas, dan proses fasilitasi dan dukungan sumber daya dari luar masyarakat yang dilakukan terhadap faktor eksternal komunitas. Keluaran pemberdayaan adalah keberdayaan masyarakat bidang kesehatan pada program Desa Siaga meliputi kemampuan mengidentifikasi masalah kesehatan lokal dan kemampuan pemecahan masalah kesehatan lokal pada program Desa Siaga.

\section{Kesimpulan}

Faktor-faktor yang berpengaruh terhadap kemampuan mengidentifikasi masalah kesehatan lokal pada program Desa Siaga meliputi akses informasi kesehatan, kepemimpinan, modal sosial, dan survei mawas diri. Besarnya kontribusi akses informasi kesehatan pada kemampuan mengidentifikasi masalah kesehatan $29,48 \%$, kepemimpinan $41,86 \%$, survei mawas diri $40,07 \%$, secara simultan 53,2\%. Faktor-faktor yang berpengaruh terhadap kemampuan pemecahan masalah kesehatan lokal pada program Desa Siaga meliputi modal sosial dan partisipasi masyarakat. Kontribusi modal sosial pada kemampuan pemecahan masalah kesehatan berjumlah sebesar $58,98 \%$, partisipasi masyarakat $51,69 \%$, secara simultan $64,2 \%$.

\section{Saran}

Kegiatan yang disarankan untuk faktor internal komunitas yang kuat/dominan adalah advokasi kepada stakeholders; mengaktifkan rapat koordinasi; penyegaran program Desa Siaga bagi pemimpin; memperkokoh kekerabatan, kedekatan, dan saling mengenal antarwarga; meningkatkan citra pelayanan kesehatan pemerintah; memperkuat landasan norma sosial; menjalin kemitraan dengan sarana pelayanan kesehatan swasta dan organisasi masyarakat; serta meningkatkan gotong-royong. Kemudian untuk faktor eksternal komunitas yang kuat/dominan disarankan meningkatkan akses informasi kesehatan melalui sosialisasi, televisi, koran, radio daerah, selebaran, rapat koordinasi, dan surveilans berbasis masyarakat; melakukan penyegaran program Desa Siaga kepada petugas kesehatan; menyusun struktur organisasi dan tata kerja dan membuat program Desa Siaga lintas program; meningkatkan kemampuan manajemen program Desa Siaga; mereorganisasi dan merevitalisasi Tim Pembina program Desa Siaga; menyusun SOP pelayanan poskesdes; serta memantau dan membina pelaksanaan survei mawas diri dan musyawarah masyarakat desa. Terakhir, pengembangan proses pemberdayaan masyarakat bidang kesehatan disarankan untuk diarahkan pada proses pemberdayaan dan pemanfaatan sumber daya di dalam masyarakat serta proses fasilitasi dan dukungan dari luar masyarakat. Pengembangan keluaran pemberdayaan masyarakat bidang kesehatan diarahkan pada keberdayaan masyarakat bidang kesehatan meliputi kemampuan mengidentifikasi masalah kesehatan lokal dan kemampuan pemecahan masalah kesehatan.

\section{Daftar Pustaka}

1. United Nations Development Programme. Overcoming barriers: mobility and development. Human Development Indices; 2011. Available from: http://hdr.undp.org/en/statistics/data/hdi.

2. Keleher H, MacDougall C. Understanding health a determinants ap- 
proach. 2nd Ed. Australia dan New Zealand: Oxford University Press; 2009.

3. Kementerian Perencanaan Pembangunan Nasional Badan Perencanaan Pembangunan Nasional. Laporan pencapaian tujuan pembangunan milenium Indonesia 2010. Jakarta: Kementerian Perencanaan Pembangunan Nasional/Badan Perencanaan Pembangunan Nasional; 2010.

4. Susilo W. Wajah buram MDGs di Indonesia. Jakarta: Kompas; 2010.

5. Departemen Kesehatan Republik Indonesia. Pedoman pengembangan desa siaga. Lampiran Keputusan Menteri Kesehatan Republik Indonesia Nomor 564/Menkes/VIII/2006. Jakarta; 2006.

6. World Health Organization. Primary health care now more than ever. The World Health Report; 2008.

7. Pemerintah Republik Indonesia, United Nations International Children's Emergency Fund. Panduan umum pemberdayaan masyarakat di bidang kesehatan ibu dan anak. Jakarta; 1999.

8. Fleming ML, Parker E. Health promotion: principles and practice in the Australian context. 3rd ed. Sydney: Ligare Book Printer; 2007.

9. Lewis GH, Sheringham J, Kalim K, Crayford TJ. Mastering public health a postgraduate guide to examinations and revalidation. Australia: Royal Society of Medicine Press Ltd. Elsevier; 2008.

10. Ife, Tesoriero F. Community development: community-based alternatives in an age of globalisation. Pearson Education Australia. Unit 4. Level 2. 14 Aquatic Drive Frenchs Fores NSW; 2010.

11. Rehn NS, Ovretveit J, Laamanen R, Suominen S, Sundel J, Brommels M. Determinants of health promotion action: comparative analysis of local voluntary associations in four municipalities in Finland. Health Promotion International. 2006; 21 (4): 274-83.

12. House JS, Williams DR. Understanding and reducing socioeconomic and racial/ethnic disparities in health. In: Syme SL, Reeder LG, editors. Promoting Health Intervention Strategies From Social and Behavioral Research. 3rd ed. Washington DC: National Academy Press; 2002. p. 81-116.

13. Collins T. Models of health: pervasive, persuasive and politically charged. In: Sidell M, Jones L, Katz J, Paberdy A, Douglas J, editors. Debate and Dilemmas in Promoting. 2nd ed. New York: Palgrave MacMillan; 2003. p. 62-8.

14. Mardikanto T. Model-model pemberdayaan masyarakat. 1st ed. Surakarta: Kerjasama Fakultas Pertanian UNS dengan UPT Penerbitan dan Percetakan UNS (UNS Press); 2010.

15. Padgett DK. Qualitative and mixed methods in public health. London: Sage Publication Asia Pacific Pte. Ltd; 2012.

16. Hawe P, Shiell A. social capital and health promotion. In: Sidell M, Jones L, Katz J, Peberdy A, Douglas J, editors. Debates and Dilemmas in Promoting Health. 2nd ed. The Open University. Palgrave Mac Millan; 2000. p. 40-7.

17. Kasmel A, Andersen PT. Measurement of community empowerment in three community programs in Rapla (Estonia). International Journal of Environmental Research and Public Health. 2011; 8: 799-817.

18. Gallaway JH, Bernasek A. Literacy and women's empowerment in Indonesia: implications for policy. Journal of Economic Issues/June. 2004; 38 (2): 319-25.

19. Ahmed I, Creanga AA, Gillespie DG, Tsui AO. Economic status, education and empowerment: implications for maternal health service utilization in developing countries. Population, Family, and Reproductive Health Department. Johns Hopkins Bloomberg School of Public Health. Baltimore. Maryland: United States of America; 2010.

20. Sumardjo. Kepemimpinan dan pengembangan kelembagaan pedesaan: kasus kelembagaan ketahanan pangan. In: Yustina I, Sudradjat A, editors. Membentuk Pola Perilaku Manusia Pembangunan. Bogor: IPB Press; 2003. p. 151-69.

21. Tarner BS. Citizenship and health as a scarce resource. In: Germov J, editor. Second Opinion an Introduction to Health Sociology. 2nd ed. Singapore: Oxford University Press; 2003. p. 399.

22. Kawachi I, Kennedy BP, Lochner K, Prothrow S. Social capital, income inequality and mortality. American Journal of Public Health. 1997; 87 (9): 1491-98.

23. Yuasa M, De Sa RF, Pincovsky S, Shimanouchi N. Emergence model of social and human capital and its application to the healthy municipalities project in Northeast Brazil. Health Promotion International. 2007; 22 (4): 292-8.

24. Sampson RJ, Morenoff JD. Public health and safety in context: lesson from community-level theory on social capital. In: Syme SL, Reeder LG, editors. Promoting Health Intervention Strategies From Social and Behvioral Research. 3rd ed. Washington, DC United State of America: National Academy Press; 2000. p. 366-85.

25. Talbot L, Verrinder G. Promoting health the primary health care approach. 3rd ed. Australia: Elsevier Australia; 2005. 